\title{
Impact of SiC Devices on Hybrid Electric and Plug-in Hybrid Electric Vehicles
}

\author{
Hui Zhang ${ }^{1}$, Leon M. Tolbert ${ }^{1,2}$, Burak Ozpineci ${ }^{2}$ \\ hzhang18@utk.edu, tolbert@utk.edu,ozpinecib@ornl.gov
}

\author{
${ }^{1}$ Electrical Engineering and Computer Science \\ The University of Tennessee \\ Knoxville, TN 37996-2100
}

\author{
${ }^{2}$ Power Electronics \& Electric Machinery Research Center \\ Oak Ridge National Laboratory \\ Knoxville, TN 37932
}

\begin{abstract}
The application of $\mathrm{SiC}$ devices (as battery interface, motor controller, etc.) in a hybrid electric vehicle (HEV) will benefit from their high-temperature capability, high-power density, and high efficiency. Moreover, the light weight and small volume will affect the whole power train system in a HEV, and thus performance and cost. In this work, the performance of HEVs is analyzed using PSAT (Powertrain System Analysis Tool, vehicle simulation software). Power loss models of a $\mathrm{SiC}$ inverter are incorporated into PSAT powertrain models in order to study the impact of SiC devices on HEVs. Two types of HEVs are considered. One is the 2004 Toyota Prius HEV, the other is a plug-in HEV (PHEV), whose powertrain architecture is the same as that of the 2004 Toyota Prius HEV. The vehicle-level benefits from the introduction of the $\mathrm{SiC}$ devices are demonstrated by simulations. Not only the power loss in the motor controller but also those in other components in the vehicle powertrain are reduced. As a result, the system efficiency is improved and the vehicles consume less energy and emit less harmful gases. It also makes it possible to improve the system compactness with simplified thermal management system. For the PHEV, the benefits are more distinct. Especially, the size of battery bank can be reduced for optimum design.
\end{abstract}

Keywords - Silicon carbide (SiC), inverter, hybrid electric vehicle (HEV), Plug-in HEV (PHEV), PSAT.

\section{INTRODUCTION}

As the issues of natural resource depletion and environmental impacts have gained greater visibility, the hybrid electric vehicle (HEV) market has rapidly expanded. The application of $\mathrm{SiC}$ devices (as battery interface, motor controller, etc.) in an HEV has merit because of their hightemperature capability, high-power density, and high efficiency. Moreover, the light weight and small volume will affect the whole power train system in a HEV, and thus performance and cost.

In this work, the performance of two HEVs is analyzed using PSAT (Powertrain System Analysis Tool, vehicle simulation software). Power loss models of a $\mathrm{SiC}$ inverter are incorporated into PSAT models in order to study the impact of $\mathrm{SiC}$ devices on HEVs. Two types of HEVs are considered. One is the 2004 Toyota Prius HEV, which has a split powertrain architecture shown in Fig. 1. The other is a plug-in HEV (PHEV), whose powertrain architecture is similar to that of the

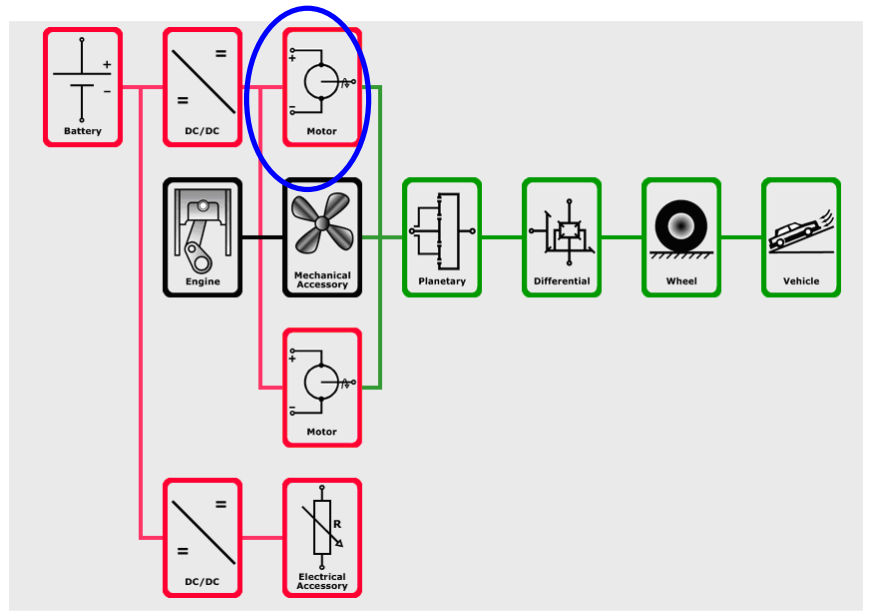

Fig. 1. Powertrain architecture of 2004 Toyota Prius HEV.

2004 Toyota Prius HEV, but has a pure electrical operation range. The $\mathrm{SiC}$ devices are applied to the primary motor marked in Fig. 1 as a 3-phase DC/AC inverter to take the place of the conventional Si inverter. The vehicle-level benefits from the introduction of the $\mathrm{SiC}$ devices are demonstrated by simulations.

\section{MODELING}

PSAT provides a programming environment based on MATLAB. In order to simulate using different inverter designs, the built-in motor model is revised and a new inverter model which has the capability to calculate its power loss and efficiency is created using MatLab SimuLink. Fig. 2 (a) compares the new model to the PSAT model. The layout of DC/AC inverter is shown in Fig. 2 (b), which is composed of six SiC JFETs and six SiC Schottky diodes. The devices used in the simulations are listed in Table I, and their characteristics are presented in Table II. Then, the inverter model is based on the following equations [1][2]:

$$
\begin{aligned}
P_{I n v, S i C} & =6 \times\left(P_{J, \text { cond }}+P_{J, s w}+P_{J \leftarrow D}+P_{D, \text { cond }}+P_{D, s w}\right) \\
P_{J, c o n d} & =I^{2} R_{J}\left(\frac{1}{8}+\frac{1}{3 \pi} M \cos \phi\right)
\end{aligned}
$$




$$
\begin{aligned}
& P_{J, s w}=\frac{H f_{s}}{2 \pi}\left\{\begin{array}{l}
\frac{G_{1}}{\sqrt{G_{1}^{2}-I^{2}}}\left[\pi+2 \tan ^{-1}\left(\frac{I}{\sqrt{G_{1}^{2}-I^{2}}}\right)\right] \\
+\frac{G_{2}}{\sqrt{G_{2}^{2}-I^{2}}}\left[-\pi+2 \tan ^{-1}\left(\frac{I}{\sqrt{G_{2}^{2}-I^{2}}}\right)\right]
\end{array}\right\} \\
& H=\frac{1}{3} \varepsilon E_{c} V A\left(\frac{V}{V_{B}}\right)^{1 / 2} G_{1}=g_{m}\left(V_{G H}-V_{t h}\right) G_{2}=g_{m}\left(V_{t h}-V_{G L}\right) \\
& P_{J \leftarrow D}=f_{s}\left[\frac{V I t_{r r}}{\pi(S+1)}+\frac{V}{4} \sqrt{\frac{V}{V_{0}}}\left(\frac{d I}{d t}\right) \frac{t_{r r}^{2}}{(S+1)^{2}}\right] \\
& P_{D, \text { cond }}=I^{2} \cdot R_{D}\left(\frac{1}{8}-\frac{1}{3 \pi} M \cos \phi\right)+I \cdot V_{D} \cdot\left(\frac{1}{2 \pi}-\frac{M \cos \phi}{8}\right) \\
& P_{D, s w}=\left(\frac{V}{V_{0}}\right)^{1.5} P_{D, s w 0}=f_{s} \frac{V}{4 S} \sqrt{\frac{V}{V_{0}}}\left(\frac{d I}{d t}\right)\left(\frac{S t_{r r}}{S+1}\right)^{2}
\end{aligned}
$$

The power loss of an inverter is the sum of the conduction loss (2) and switching loss (3) and (4) of the JEFTs and the conduction loss (5) and switching loss (6) of the diodes. For symbols' definitions, refer to Appendix I.

The system programs for the HEVs can be generated by PSAT, which is shown in Fig. 3. In the following two sections, simulations of the HEV and PHEV will be discussed respectively.

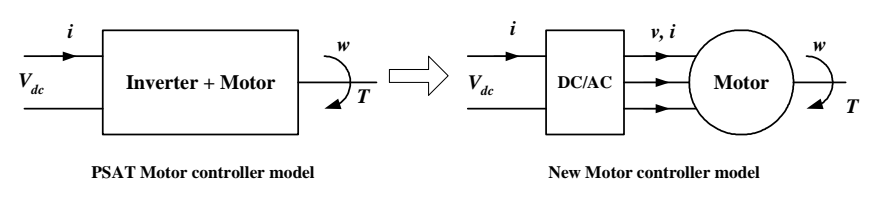

(a)

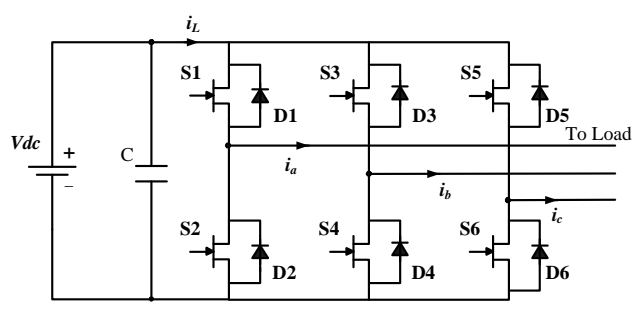

(b)

Fig. 2. (a) Comparison of PSAT model and the new model.

(b) Topology of a standard 3-phase converter.

TABLE I. DeVICES Used IN THE CONVERTERS

\begin{tabular}{|c|c|c|c|}
\hline Item & $\begin{array}{c}\text { Voltage } \\
\text { rating }\end{array}$ & $\begin{array}{c}\text { Current } \\
\text { rating }\end{array}$ & Part number \\
\hline SiC JFETs & 1200 & $14 \mathrm{~A} \times 21$ & SiCED \\
\hline SiC Schottky diodes & 1200 & $10 \mathrm{~A} \times 30$ & Cree, CSD10120 \\
\hline Si IGBT Module & 1200 & $300 \mathrm{~A}$ & Powerex, CM300DY-24NF \\
\hline
\end{tabular}

Note: $\times 21$ and $\times 30$ represent the number of devices.
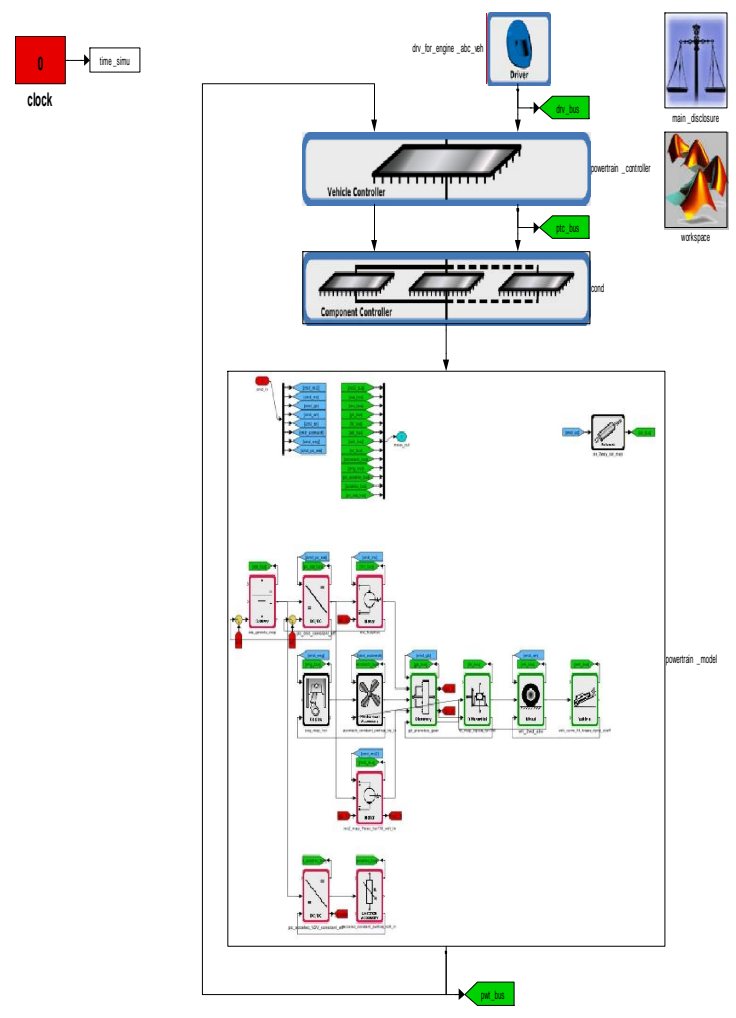

(a) Vehicle model
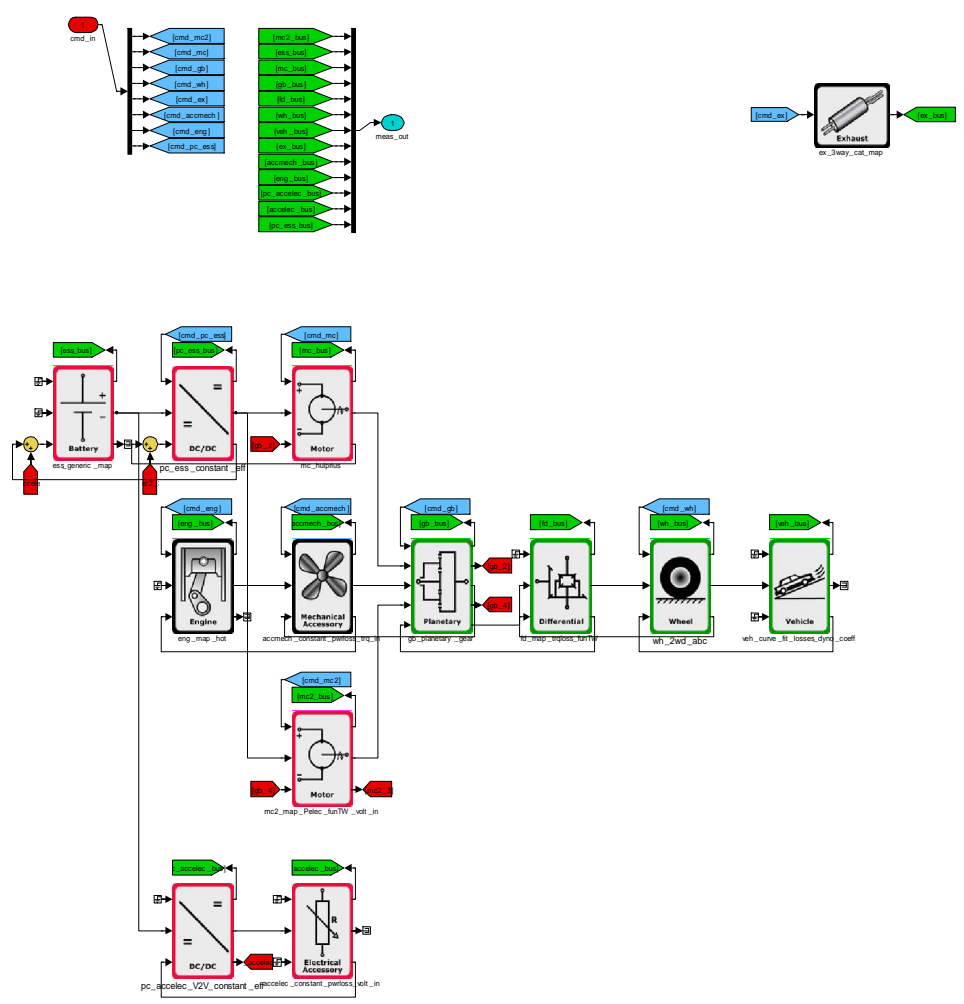

(b) Powertrain model

Fig. 3. Simulink model for the HEVs. 
TABLE II. DeVICE CharaCteristics (AT RoOM TEMPERATURE)

\begin{tabular}{|l|c|c|}
\hline \multicolumn{1}{|c|}{ Characteristics } & $\mathrm{Si}$ & $\mathrm{SiC}$ \\
\hline IGBT/JFET on-state resistance & $6.6 \mathrm{~m} \Omega$ & $7.4 \mathrm{~m} \Omega(0.156 \Omega / 21)$ \\
\hline IGBT/JFET voltage drop when $\mathrm{I}=0$ & $0.83 \mathrm{~V}$ & $0.0 \mathrm{~V}$ \\
\hline IGBT/JFET transconductance & $61.2 \mathrm{~S}$ & $14.7 \mathrm{~S}(0.7 \mathrm{~S} \times 21)$ \\
\hline Diode on-state resistance & $8.6 \mathrm{~m} \Omega$ & $2.1 \mathrm{~m} \Omega(63.8 \mathrm{~m} \Omega / 30)$ \\
\hline Diode reverse recovery charge & $13 \mu \mathrm{C}$ & $0.84 \mu \mathrm{C}(28 \mathrm{nC} \times 30)$ \\
\hline
\end{tabular}

\section{2004 Toyota Hybrid ELECTRIC VehicLE}

Simulations are run for both a HEV with a SiC inverter and one with a $\mathrm{Si}$ inverter for a UDDS (US EPA-Urban Dynamometer Driving Schedule, which represents city driving conditions of light duty vehicles, see Fig. 4) cycle. Assume the two inverters have the same size heatsink and cooling conditions, and the switching frequency is $20 \mathrm{kHz}$. The initial SOC is equal to final SOC. As for inverter itself, the benefits of the $\mathrm{SiC}$ devices are shown in Fig. 5. Due to the lower power losses of the $\mathrm{SiC}$ devices, the junction temperatures of the $\mathrm{SiC}$ devices are much lower than those of Si ones (see Fig. 5 (a) and (b)). As a result, the power loss of the $\mathrm{SiC}$ inverter is reduced, and its efficiency is much improved (see Fig. 5(c) and (d)). The quantified comparisons of $\mathrm{SiC}$ and $\mathrm{Si}$ inverters are given in Table III.

Furthermore, the benefits of the SiC-based inverter are also seen at the system level. For example, the system efficiency is improved from $31.3 \%$ to $37.2 \%$ (increased by $18.8 \%$, corresponding to $3020 \mathrm{~kJ}$ ) due to the energy saving in other powertrain components (such as engine, generator, mechanical accessories, and etc.) and the better capability of recuperating braking energy. As a result, the fuel economy is improved from 4.15 to 3.39 liter/100km (decreased by 18.3\%). More quantitative results are summarized in Table III.

For the Si-based system, the fuel economy is very close to the manufacturer's data $(3.92$ liter $/ 100 \mathrm{~km})$ even though different $\mathrm{Si}$ devices and cooling method were used in the simulations. For the SiC-based system, the results were based on the predicted characteristics of future devices. They were overestimated for today's prototype $\mathrm{SiC}$ devices, but are expected to be achieved in 10 years as improvements are made.

In addition, as shown in Fig. 5 (a) and (b), the junction

TABLE III. SUMMARY OF IMPACT OF THE SIC INVERTER ON THE HEV (2004 TOYOTA PRIUS)

\begin{tabular}{|c|c|c|c|c|}
\hline \multicolumn{2}{|r|}{ Description } & $\mathrm{Si}$ & $\mathrm{SiC}$ & Improve\% \\
\hline \multirow{4}{*}{$\begin{array}{l}\bar{D} \\
\frac{0}{0} \\
\frac{8}{0} \\
.00 \\
0\end{array}$} & JFETs/IGBTs average junction temperature $\left({ }^{\circ} \mathrm{C}\right)$ & 59 & 30 & 49.2 \\
\hline & Diodes average junction temperature $\left({ }^{\circ} \mathrm{C}\right)$ & 57 & 30 & 47.4 \\
\hline & Average inverter power loss (W) & 829 & 85 & 89.7 \\
\hline & Average inverter efficiency $(\%)$ & 71.4 & 89.6 & 25.5 \\
\hline \multirow{10}{*}{ 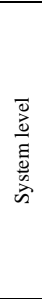 } & Fuel economy (liter/100km) & 4.15 & 3.39 & 18.3 \\
\hline & $\mathrm{CO}_{2}$ emissions $(\mathrm{g} / \mathrm{m})$ & 0.10 & 0.08 & 20.0 \\
\hline & Energy loss in generator $(\mathrm{kJ})$ & 325 & 276 & 15.1 \\
\hline & Energy loss in motor (include inverter)(kJ) & 2000 & 975 & 51.3 \\
\hline & Energy loss in mechanical accessory $(\mathrm{kJ})$ & 153 & 131 & 14.4 \\
\hline & Energy loss in engine $(\mathrm{kJ})$ & 2916 & 2391 & 18.0 \\
\hline & Total fuel energy use $(\mathrm{kJ})$ & 16000 & 13100 & 18.1 \\
\hline & Percentage braking energy recuperated $(\mathrm{kJ})$ & 61 & 80 & 31.1 \\
\hline & System efficiency $(\%)$ & 31.3 & 37.2 & 18.8 \\
\hline & Mass of fuel needed to travel $515 \mathrm{~km}(\mathrm{~kg})$ & 16 & 13 & 18.8 \\
\hline
\end{tabular}

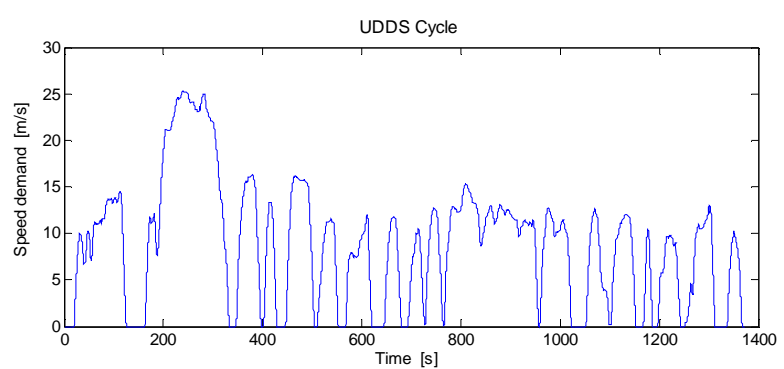

Fig. 4. UDDS cycle.

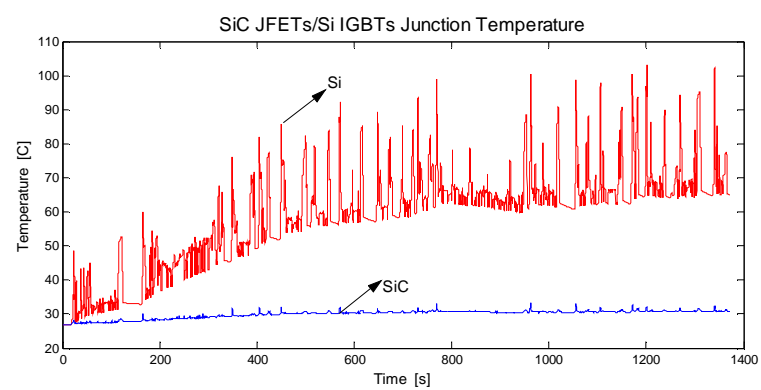

(a)

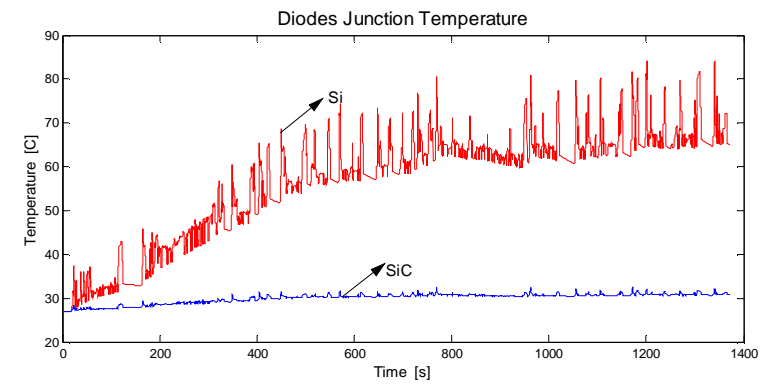

(b)

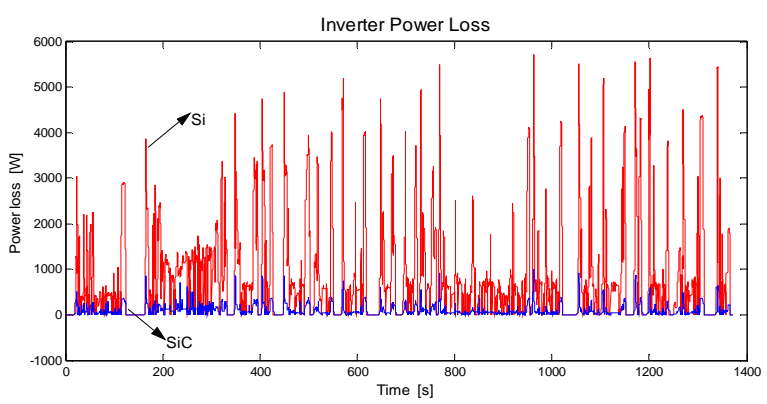

(c)

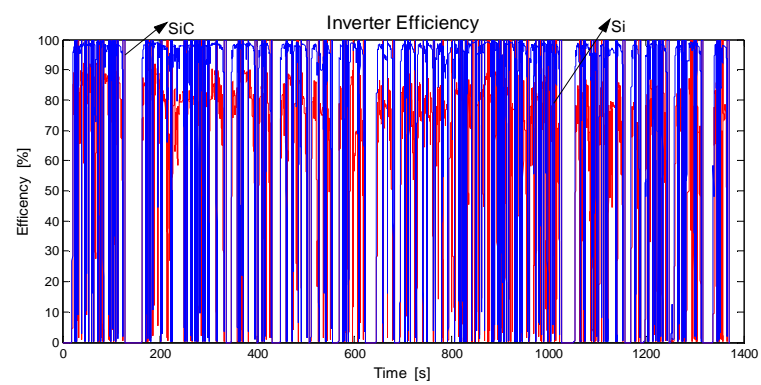

(d)

Fig. 5. Comparison of the $\mathrm{SiC}$ and $\mathrm{Si}$ inverters in the HEV. 
temperatures of the $\mathrm{SiC}$ devices are low. Taking the high temperature capability of the $\mathrm{SiC}$ devices into account, the cooling system of the $\mathrm{SiC}$ inverter can be downgraded. By simulation, if the size of heatsink is reduced to half, the efficiency of the inverter will have no substantial change and so the efficiency of the HEV will also not change even with the smaller heatsink.

\section{Plug-IN Hybrid EleCtric Vehicle}

A PHEV is designed with all-electric operation capability for several kilometers and functions as a pure electric vehicle during the all-electric range (AER) in urban driving. It has similar components and powertrain architecture with an $\mathrm{HEV}$, but has the ability to recharge a larger energy storage system (such as a battery bank) from off-board electrical power. Thus, PHEVs are more effective in decreasing fuel consumption and reducing air pollution compared to HEVs [3].

The PHEV studied here is designed with $48 \mathrm{~km}$ AER, which is approximately 4 UDDS cycles. It has the same powertrain architecture and components as the 2004 Toyota Prius HEVs, except the capacity of the battery system is larger. By the simulations, the optimized size of the battery bank for a plug-in vehicle with the $\mathrm{SiC}$ inverter and that with the $\mathrm{Si}$ inverter are $5.1 \mathrm{kAh}$ and $7.8 \mathrm{kAh}$, respectively, compared to 1.1 kAh of the 2004 Toyota Prius HEVs (assume initial SOC 90\% and final SOC 30\%). Thus, for this design, using a SiC-based inverter can reduce the size of the battery bank by $34.6 \%$. Assuming the same heatsink design for both inverters, simulations were run for both systems for 4 UDDS cycles. The performance of the two inverters is presented in Fig. 6. Again, due to the lower power losses of the $\mathrm{SiC}$ devices, the junction temperatures of the $\mathrm{SiC}$ devices are much lower than those of the Si ones (see Fig. 6 (a) and (b)). As a result, the power loss of the $\mathrm{SiC}$ inverter is reduced, and its efficiency is much improved (see Fig. 6 (c) and (d)). The quantified comparison for the $\mathrm{SiC}$ and $\mathrm{Si}$ inverters are given in Table IV.

Furthermore, like the $\mathrm{HEV}$, the benefits of the SiC-based inverter are also seen at the system level. For example, the system efficiency is improved from $62.6 \%$ to $79.6 \%$ (increased by $27.2 \%$, corresponding to $7100 \mathrm{~kJ}$ ), and the average electricity consumption during the drive cycle is reduced from 447.8 to $301.7 \mathrm{~J} / \mathrm{m}$ (decreased by $32.6 \%$ ). Other quantitative results are summarized in Table IV.

Since the junction temperatures of the $\mathrm{SiC}$ devices are low,

TABle IV. Summary of IMPACT OF THE SiC INVERTER ON THE Plug-IN HEV DURING AER (WITH THE SAME COOLING CONDITION)

\begin{tabular}{|c|c|c|c|c|}
\hline \multicolumn{2}{|r|}{ Description } & $\mathrm{Si}$ & $\mathrm{SiC}$ & Improve \% \\
\hline \multirow{4}{*}{ 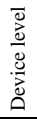 } & JFETs/IGBTs average junction temperature $\left({ }^{\circ} \mathrm{C}\right)$ & 49 & 36 & 26.5 \\
\hline & Diodes average junction temperature $\left({ }^{\circ} \mathrm{C}\right)$ & 45 & 37 & 17.8 \\
\hline & Average inverter power loss (W) & 1187 & 141 & 88.1 \\
\hline & Average inverter efficiency $(\%)$ & 69.7 & 87.6 & 25.7 \\
\hline \multirow{5}{*}{ 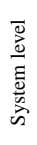 } & Electricity consumption $(\mathrm{J} / \mathrm{m})$ & 447.8 & 301.7 & 32.6 \\
\hline & Energy loss in motor (include inverter)(kJ) & 9040 & 2150 & 76.2 \\
\hline & Total energy use $(\mathrm{kJ})$ & 21900 & 15000 & 31.5 \\
\hline & Percentage braking energy recuperated $(\mathrm{kJ})$ & 53 & 78 & 47.2 \\
\hline & System efficiency $(\%)$ & 62.6 & 79.6 & 27.2 \\
\hline
\end{tabular}

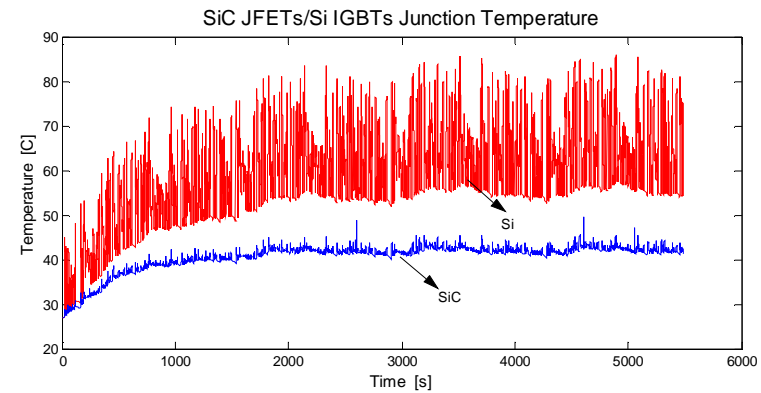

(a)

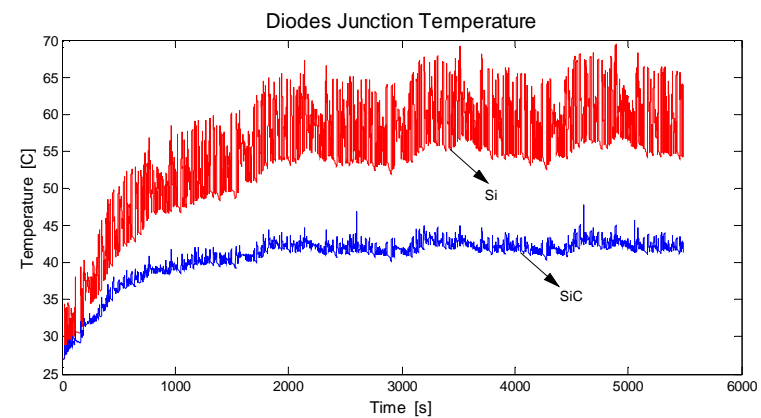

(b)

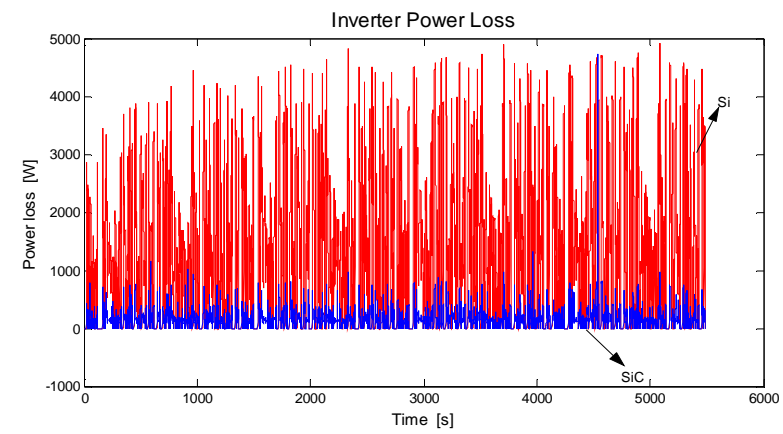

(c)

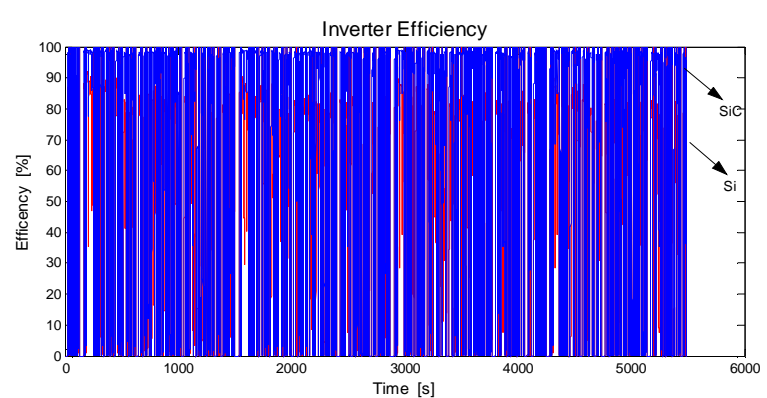

(d)

Fig. 6. Comparison of the SiC and Si inverters in the PHEV during AER.

more study is done by reducing the size of the heatsink of the $\mathrm{SiC}$ inverter. The junction temperature response is shown in Fig. 7. It is found that the efficiency of the $\mathrm{SiC}$ inverter is lowered by only $0.5 \%$, and at system level, the system efficiency is lowered by $0.3 \%$ with the smaller heatsink. Thus, it is feasible to use a small heatsink for the SiC inverter.

As a summary, for the PHEVs with optimized design, the application of the SiC inverters can have a small heatsink and 


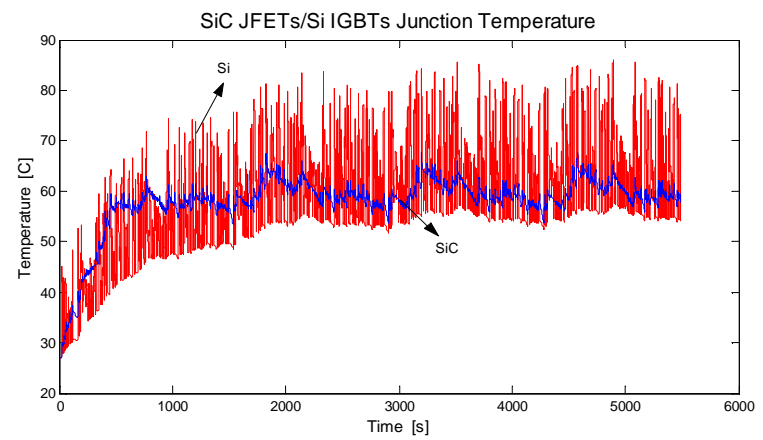

(a)

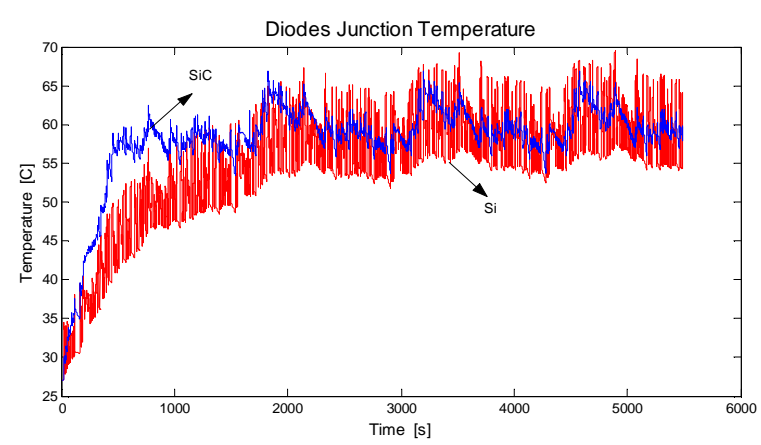

(b)

Fig. 7. Junction temperatures of the $\mathrm{SiC}$ devices with a smaller heatsink.

battery bank, but high system efficiency.

To compare with HEVs, the equivalent fuel economy of a PHEV is estimated as follows:

(1) Convert electricity economy in AER to equivalent fuel economy (Fuel efficiency of the HEV is $32207 \mathrm{~kJ} / \mathrm{liter}$ )

PHEV with the SiC inverter:

$$
\frac{301.7 \mathrm{~J} / \mathrm{m}}{32207 \mathrm{~kJ} / \text { liter }}=0.94 \text { liter } / 100 \mathrm{~km}
$$

PHEV with the Si inverter:

$$
\frac{447.8 \mathrm{~J} / \mathrm{m}}{32207 \mathrm{~kJ} / \text { liter }}=1.39 \text { liter } / 100 \mathrm{~km}
$$

(2) By report [4], for a PHEV with $48 \mathrm{~km} \mathrm{AER,} \mathrm{the}$ fraction of kilometers potentially displaced by electricity is about $43 \%$. Then, the equivalent fuel economy of the PHEV is as follows:

PHEV with the SiC inverter:

$0.94 \times 43 \%+3.39 \times 57 \%=2.34$ liter $/ 100 \mathrm{~km}$

PHEV with the Si inverter:

$1.39 \times 43 \%+4.15 \times 57 \%=2.96$ liter $/ 100 \mathrm{~km}$

Therefore, the application of the $\mathrm{SiC}$ inverter in the PHEV improves the fuel economy by $20.9 \%$, which is larger than that for the conventional $\mathrm{HEV}(18.3 \%)$. It indicates that using a $\mathrm{SiC}$ inverter in a PHEV has more impact than in a HEV.

\section{CONCLUSIONS}

Application of the SiC devices on the two HEVs reduces not only the power loss in the motor drive but also those in other components in the vehicle powertrain. As a result, the system efficiency is improved, and the vehicles consume less energy and emit less harmful emissions. It also makes it possible to improve the system compactness with simplified thermal management system. For the PHEV, the benefits are more distinct. Especially, the size of battery bank can be reduced for optimum design.

\section{REFERENCES}

[1] H. Zhang, L. M. Tolbert, B. Ozpineci, M. Chinthavali, "Power losses and thermal modeling of $4 \mathrm{H}-\mathrm{SiC}$ VJFET inverter," IEEE Industry Applications Society Annual Meeting, October 2-6, 2005, Hong Kong, China, pp. 2630-2634.

[2] H. Zhang, L. M. Tolbert, B. Ozpineci, M. Chinthavali, "A SiC-based converter as a utility interface for a battery system," IEEE Industry Applications Society Annual Meeting, October 8-12, 2006, Tampa, Florida, pp.346-350.

[3] A. Francisco, A. A. Frank, " Drive system analysis and optimization for plug-in hybrid electric vehicles," University of California-Davis, 2001.

[4] P. Denholm, W. Short, "An evaluation of utility system impacts and benefits of optimally dispatched plug-in hybrid electric vehicles," Technical Report, NREL/TP-620-40293, http://www.nrel.gov/docs/fy07 osti/40293.pdf, October, 2006.

[5] A. Simpson, "Cost-benefit analysis of plug-in hybrid electric vehicle technology," 22nd International Battery, Hybrid and Fuel Cell Electric Vehicle Symposium and Exhibition (EVS-22), October 23-28, 2006, Yokohama, Japan.

[6] Powertrain System Analysis Toolkit (PSAT) Advanced Features, Argonne National Laboratory.

[7] M. S. Duvall, "Battery evaluation for plug-in hybrid electric vehicles," 2005 IEEE Vehicle Power and Propulson Conference, 7-9 Sept. 2005, Chicago, Illinois, USA, pp. 338-343.

[8] C. W. Ayers, J. S. Hsu, L. D. Marlino, C. W. Miller, G. W. Ott Jr., C. B. Oland, "Evaluation of 2004 Toyota Prius hybrid electric drive system interim report," ORNL/TM-2004/247, UT-Battelle, Oak Ridge National Laboratory, Oak Ridge, TN, USA, November 2004.

[9] F. An, A. Vyas, J. Anderson, D. Santini, "Elvaluating commercial and prototype HEVs," SAE 2001 World Congress, Detroit, MI, USA, March. 2001.

[10] S. Inman, M. El-Gindy, D.C. Haworth, "Hybrid electric vehicles technology and simulation: Literature review," International Journal of Heavy Vehicle Systems, vol. 10, no..3, 2003, pp. 167 - 187.

\section{APPENDIX I. SYMBOLS}

\begin{tabular}{|ll|ll|}
\hline$V_{D}$ & Diode voltage when current is 0 & $V$ & DC bus voltage \\
$R_{D}$ & On resistance of diode & $I$ & Peak forward current \\
$R_{J}$ & On resistance of JFET & $\phi$ & Modulation index \\
$f_{s}$ & Switching frequency & $E_{c}$ & Breakdown voltage \\
$t_{r r}$ & Reverse recovery time of diode & $\varepsilon$ & Dielectric constant \\
$P_{I n v, S i C}$ & Power loss of SiC inverter & $g_{m}$ & Transconductance \\
$P_{J, c o n d}$ & Conduction loss of JFET & $V_{G H}$ & Highest gate voltage \\
$P_{J, s w}$ & Switching loss of JFET & $V_{G L}$ & Lowest gate voltage \\
$P_{D, c o n d}$ & Conduction loss of diode & $V_{t h}$ & Threshold voltage \\
$P_{D, s w}$ & Switching loss of diode & $S$ & Snappiness factor of diode \\
$P_{J \leftarrow D}$ & JFET loss due to the reverse & $A$ & Active area of device \\
recovery of the anti-paralleled diode & & \\
\hline
\end{tabular}

